\title{
Epidemiology of hepatitis B virus infection in India
}

\author{
B N Tandon, S K Acharya, A Tandon
}

\begin{abstract}
The average estimated carrier rate of hepatitis $B$ virus (HBV) in India is $4 \%$, with a total pool of approximately 36 million carriers. Wide variations in social, economic, and health factors in different regions may explain variations in carrier rates from one part of the country to another. Professional blood donors constitute the major high risk group for $\mathrm{HBV}$ infection in India, with a hepatitis B surface antigen positivity rate of $14 \%$. Blood transfusions represent the most important route of $\mathrm{HBV}$ transmission among adults. However, most of India's carrier pool is established in early childhood, predominantly by horizontal spread due to crowded living conditions and poor hygiene. Acute and subacute liver failure are common complications of viral hepatitis in India and HBV is reckoned to be the aetiological agent in $42 \%$ and $45 \%$ of adult cases, respectively. $\mathrm{HBV}$ is reported to be responsible for $70 \%$ of cases of chronic hepatitis and $80 \%$ of cases of cirrhosis of the liver. About $60 \%$ of patients with hepatocellular carcinoma are $\mathrm{HBV}$ marker positive. Small numbers of patients have been reported to be infected with the pre-core mutant virus but none with the $S$ mutant. Coinfection with hepatitis $\mathbf{C}$ virus or hepatitis delta virus is comparatively uncommon. In conclusion, hepatitis $B$ is a major public health problem in India and will continue to be until appropriate nationwide vaccination programmes and other control measures are established.
\end{abstract}

(Gut 1996; 38 (suppl 2): S56-S59)

Keywords: hepatitis B virus, India, professional blood donors, acute liver failure, subacute liver failure.

Pushpawati Singhania Research Institute for Liver and Digestive Diseases, New Delhi, India

B N Tandon

A Tandon

All India Institute of Medical Sciences, New Delhi, India

S K Acharya

Correspondence to: Professor B N Tandon, Director, Pushpawati Singhania Research Institute for Liver and Digestive Diseases, M-52, Greate Kailash-II, New Delhi110048 , India. which may explain the differences in HBV carrier rates reported by investigators in different parts of the country ${ }^{5-8}$ (and S K Naik, S P Thyagarajan, Y K Chawla, personal communications). The lowest prevalence
$(0.97 \%)$ has been reported in Chandigarh in northern India (Y K Chawla, personal communication) and the highest (5.5\%, in Madras in southern India (S P Thyagarajan, personal communication). Anti-HBs antibody positivity, indicating past infection, follows the same epidemiological pattern as that of HBsAg carriage and about $14 \%$ of healthy volunteer blood donors are estimated to be anti-HBs positive. ${ }^{5}$ Limited studies of rural versus urban populations suggest that their HBV carrier and infection rates are similar. Overall, the HBV carrier rate in India has not changed during the last decade (Y K Chawla, personal communication) although the carrier pool has increased by nearly 5 million due to an increase in the total population of the country.

\section{HBeAg positivity}

Hepatitis B e antigen ( $\mathrm{HBeAg}$ ) positivity, which denotes viral replication and high infectivity, has been reported in $7 \cdot 8 \%$ of pregnant females in north India. ${ }^{9}$ Among HBsAg positive subjects in Madras and Chandigarh, recent reports show $\mathrm{HBeAg}$ positivity rates of $34.2 \%$ and $47 \%$, respectively (S P Thyagarajan, Y K Chawla, personal communications). These rates are significantly higher than those recorded in an earlier report from Delhi, ${ }^{9}$ and a multicentre study is needed to resolve the reasons for such differences. No large study has yet been carried out to estimate $\mathrm{HBeAg}$ positivity rates among Indian children, or to investigate the dynamics of natural clearance of $\mathrm{HBeAg}$.

\section{Risk groups}

\section{PROFESSIONAL BLOOD DONORS}

Professional blood donors constitute nearly $40 \%$ of all blood donors in India. They represent the major high risk group for $\mathrm{HBV}$ infection in this country, with an HBsAg positivity rate of $15 \%$ - about five times the prevalence of HBsAg in healthy volunteer blood donors. 510 These professional blood donors are neither homosexual nor parenteral drug abusers, but have a low socioeconomic status and live under very poor hygienic conditions. They move from one commercial blood bank to another, and only rarely do these blood banks follow appropriate procedures for prevention of $\mathrm{HBV}$ transmission. It is very likely that the professional blood donors themselves are infected with HBV through this unsafe blood collection system. They then infect others through blood transfusions, which represent the most important route of $\mathrm{HBV}$ infection in adults in this 
country. ${ }^{11}$ A study from Delhi reported posttransfusion hepatitis in $7 \%$ of recipients, and $20 \%$ of cases were due to $\mathrm{HBV}$ infection. ${ }^{12}$

\section{OTHER HIGH RISK GROUPS}

Compared with the general population, the risk of $\mathrm{HBV}$ infection is higher in thallassaemic children and among renal dialysis patients and staff. However, a study at one of the major hospitals in Delhi did not show significantly higher rates of $\mathrm{HBsAg}$ positivity among surgeons and other health care workers with frequent occupational exposure to blood. ${ }^{5}$

\section{Perinatal versus horizontal transmission} It has been observed that pre-school children have an HBV carrier rate of between $2 \%$ and $3 \%$, which is the same as that recorded among adults in India. ${ }^{9}{ }^{10}$ This suggests that most of India's HBV carrier pool is established during early childhood. The combined factors of low HBeAg positivity rates among pregnant females, poor hygienic living conditions, and close person to person contact due to crowded living conditions have led to the conclusion that horizontal spread during early childhood accounts for about $75 \%$ of all HBV transmission in India, and less than $30 \%$ is thought to result from perinatal transmission. ${ }^{9}$

\section{Sequelae of HBV infection}

ACUTE AND SUBACUTE HEPATITIS

After the non-A, non-B (NANB) viruses (particularly hepatitis $\mathrm{E}$ virus (HEV)), $\mathrm{HBV}$ is the second most important cause of acute, subacute, and fulminant hepatitis in India. ${ }^{12} \mathrm{~A}$ decade ago, HBV was reported to be the aetiological agent of these three conditions in $42 \%$, $45 \%$, and $33 \%$ of adult cases, respectively, and this pattern remains true to this day. In the paediatric age group, however, only $9 \%$ of acute hepatitis is due to infection with HBV. ${ }^{12}$

Acute and subacute liver failure are common complications of viral hepatitis in India. Each year, approximately 70 patients with these conditions are registered at Rajgarhia Liver Unit of the All India Institute of Medical Sciences. ${ }^{13}$ Between July 1976 and December 1990,367 cases of acute hepatic failure were reported to this unit alone. ${ }^{14}$ In addition, 148 cases of subacute hepatic failure were reported between June 1981 and June $1987 .{ }^{15}$ Clear differences between these two groups of patients have been reported from this unit. ${ }^{13}$

\section{Definitions}

Acute liver failure has been defined as development of hepatic encephalopathy within four weeks of the onset of the first symptoms of hepatitis in a patient with no previous record of liver disease. ${ }^{13} 16$

Subacute liver failure has been recognised as a distinct clinical entity characterised by persistent or progressive jaundice four weeks after the onset of icterus, together with appearance of moderate or severe ascites four weeks into the post-icteric period. ${ }^{15} 17$ It has a slow, progressively deteriorating course with late development of encephalopathy, and is associated with a death rate of $75 \%$ to $80 \%$ within three to six months after the onset of illness. ${ }^{15}$ Several authors have described this condition under alternative names such as 'protracted viral hepatitis with impaired regeneration' and a 'subfulminant hepatitis'. ${ }^{14}$

\section{Aetiology}

Acute liver failure - cases of acute failure in India are almost exclusively caused by infection with hepatotrophic viruses. ${ }^{13} \mathrm{~A}$ study published about 10 years ago reported an aetiology of HBV infection in $33 \%$ of patients with acute liver failure registered at the Rajgarhia Liver Unit. ${ }^{12} \mathrm{~A}$ more recent study in a larger series of 430 patients in the same unit reported a similar pattern, with $\mathrm{HBV}$ as the aetiological agent in $27 \cdot 6 \%$ of patients with acute hepatic failure (personal communication). ${ }^{21}$ Among those diagnosed as having NANB hepatitis, $62 \cdot 4 \%$ were found to be positive for HEV-RNA determined by PCR analysis (S K Acharya, personal communication). Neither HBV mutant viruses nor hepatitis delta virus (HDV) have been reported as aetiological agents of acute liver failure in India (S K Panda, personal communication).

Subacute liver failure - as in acute liver failure, hepatotrophic viruses have been found to be the aetiological agents of subacute liver failure in nearly $100 \%$ of patients. ${ }^{15}$ Again, the NANB group of viruses (including HEV in two thirds of cases) is the most important cause of subacute liver failure, followed by HBV infection (reported in $34 \%$ of patients). ${ }^{15}$ Subacute liver failure resulting from coinfection or superinfection with HDV or hepatitis $C$ virus (HCV) is very rare.

\section{CHRONIC HEPATITIS}

Among chronic hepatitis cases, an aetiology of HBV infection has been reported in $70 \%$. An immunopathological study has suggested that $80 \%$ of cases of cirrhosis of the liver are due to chronic infection with HBV. ${ }^{19}$ Furthermore, a recent communication from Madras suggests that $61.3 \%$ of patients with hepatocellular carcinoma are positive for markers of $\mathrm{HBV}$ infection (S P Thyagarajan, personal communication).

\section{Mutant viruses}

Infection with the pre-core mutant variant of HBV has been recorded in a small series of 13 patients with HCV negative chronic hepatitis. However, no cases of infection with the HBV S mutant have yet been detected (S K Panda, personal communication).

\section{Coinfection with other viruses}

Coinfection with HCV and superinfection with HDV are both comparatively uncommon in 
India and neither has been recorded in more than $10 \%$ of patients with chronic hepatitis. ${ }^{20} 21$

\section{Conclusions}

Hepatitis B remains a significant public health problem in India and will continue to do so as long as commercial blood banks remain operational and until appropriate nationwide vaccination programmes and other control measures are established. Unfortunately, the shortfall between blood collected ( 1.5 million units per year) and blood needed ( 3 million units per year) in India means that commercial blood banks will remain profitable (and necessary) unless the number of volunteer donors increases dramatically. Furthermore, although programmes for the prevention and control of hepatitis B should represent a priority for the government and health services in India, the costs and difficulties associated with their initiation are a major problem at present.

1 Standing Committee on Projection confirming 1991 Consensus Data. Registrar General Office, GOI, New Delhi.

2 Suzuki H, Woodfield G. Viral hepatitis in Asia: summary of a plenary session. In: Nishioka K, Suzuki $\mathrm{H}$, Mishiro $\mathrm{S}$, Oda T, eds. Viral hepatitis and liver disease. Tokyo: Springer Verlag, 1994: 385-6.

3 Agarwal R, Naid SR. Prevention of hepatitis B infection: the appropriate strategy for India. Natl Med F India 1994; 7: 216-20.

4 Andre FE. Overview of a 5 year clinical experience with a yeast derived hepatitis B vaccine. Vaccine 1990; 8 (suppl): S74-8.

5 Irshad M, Joshi YK, Acharya SK, Tandon BN. Prevalence of hepatitis B virus infection in healthy persons in North India. Natl Med f India 1994; 7: 210-2.

6 Singhvi A, Putimood RB, John TJ, et al. The prevalence of markers for hepatitis B and human immunodeficiency viruses, malarial parasites, and microflora in blood donors in a large hospital in South India. F Trop Med Hyg 1990; 93: $178-82$.

7 Prasad SR, Rodrigues FM, Dhonje SP, Ramamoorthy CL. Prevalence and subtypes of hepatitis B surface antigen in the tribal population in Arunachal Pradesh. Ind f Med Res (A) 1983; 78: 300-6.

8 Joshi SH, Gorakshakar AC, Mukerjee M, et al. Prevalence of HBsAg carriers among some tribes of Madhya Pradesh. Ind $\mathcal{Y}$ Med Res $(A)$ 1990; 91: 341-3.

9 Nayak NC, Panda SK, Zuckerman AJ, Bhan MK, Guha DK. Dynamics and impact of perinatal transmission of hepatitis B virus in North India. $\mathcal{f}$ Med Virol 1987; 21: $137-45$.

10 Irshad M, Singh YN, Acharya SK. HBV-status in professional blood donors in North India. Trop Gastroenterol 1992; 13: 112-4.

11 Dasarathy S, Misra SC,. Acharya SK, Irshad M, Joshi YK, Venugopal P, Tandon BN. Prospective controlled study of post transfusion hepatitis after cardiac surgery in large referral hospital in India. Liver 1992; 12: 116-20.

12 Tandon BN, Gandhi BM, Joshi YK. Etiological spectrum of viral hepatitis and prevalence of markers of hepatitis A
and B virus infection in North India. Bull WHO 1984; 62: and $B$ virus.

13 Acharya SK, Dasarathy S, Tandon BN. Should we redefine acute liver failure? Lancet 1993; 342: 1421-2.

14 Tandon BN, Acharya SK. Fulminant hepatic failure: clinical syndrome and progress in management. In: Okita $\mathrm{K}$, ed. Frontiers in hepatology '93 Tokyo: Axel Springer Japan Publishing, 1994: 11-6.

15 Tandon BN, Joshi YK, Acharya SK. Subacute hepatic failure. Natl Med F India 1988; 1: 124-7.

16 Trey C, Davidson JS. The management of fulminant hepatic failure. In: Popper H, Schaffner F, eds. Progress in hepatic failure. In. Pork: Grune and Stratton, 1970: 282-9.

17 Tandon BN, Joshi YK, Krishnamurthy L, Tandon HD. Subacute hepatic failure: is it a distinct entity? $\mathcal{f}$ Clin Subacute hepatic failure: is
Gastroenterol 1982; 4: 362-4.

18 Acharya SK, Panda SK, Duphare H, et al. Chronic hepatitis in a large Indian Hospital. Natl Med f India 1993; 6: 202-6.

19 Nayak NC, Dhar A, Sachdeva R, et al. Association of human hepatocellular carcinoma and cirrhosis with hepatitis B virus surface and core antigen in the liver. Int $f$ Cancer 1977; 20: 643.

20 Panigrahi AK, Nanda SK, Dixit RK, Acharya SK, Zuckermann AJ, Panda SK. Diagnosis of hepatitis C virus associated chronic liver disease in India. $\mathbf{F}$ Med Virol 1994; 44: 176-9.

21 Anand AC, Gandhi BM, Acharya SK, Irshad M, Joshi YK, Gastroenterol Hepatol 1988; 3: 425-9.

\section{Discussion}

Toukan: Why is the prevalence of hepatitis B so much higher among professional blood donors than among the general population $-12 \%$ versus about $2 \%$ ?

Tandon: They are generally poor people who keep moving from one blood bank to another, and especially to those blood banks that are not properly licensed or managed. They probably acquire the infection through unsterilised needles and syringes at these poorly managed blood banks.

Toukan: Could the figures be biased by the fact that they are very poor people, and such people generally have higher hepatitis B carrier rates compared with the general population?

Tandon Some small surveys have been done to assess the prevalence of $\mathrm{HBsAg}$ in very poor urban slums. Although only small numbers of subjects are involved - probably not more than 800 - the HBsAg prevalence does not seem to be more than $3 \%$. These professional blood donors are almost certainly infected through repeated exposure at badly run blood banks. They may donate as often as every two or three weeks, even though their haemoglobin concentrations fall as low as 7 or $8 \mathrm{~g} / \mathrm{dl}$, just to make a living.

Toukan: In pregnant women who die from acute hepatitis, what is the relative importance of each of the hepatitis viruses?

Tandon: Non-A, non-B hepatitis - predominantly $\mathrm{HEV}$ - is the most important factor for high mortality and fulminant hepatic failure in pregnant women.

Toukan: What is the mortality in pregnancy from hepatitis B or A?

Tandon: The death rate for hepatitis $\mathrm{A}$ is extremely low - not more than $5 \%$. In fact, fulminant hepatitis A is very uncommon in adults. In children, however, when we find both HAV and HEV together, we often see fulminant infection. It also occurs in adults when there is superinfection of hepatitis $A$ in carriers of hepatitis B. As far as the other hepatitis viruses are concerned, HEV is the most common cause of fulminant disease - either alone or as a superinfection in hepatitis B carriers. Hepatitis $C$ is a very rare cause of fulminant hepatitis.

Gust: Is all blood in India screened for HBsAg? Tandon: Legally, all blood banks in India should take only voluntary donors and blood should be screened for HBsAg, but monitoring is extremely poor, as it is in two thirds of the world today. Only about a week ago, it was recorded that the Red Cross blood supply in Bombay was contaminated with HIV and $\mathrm{HBV}$, and the blood bank was closed down.

Gust: What proportion of your fulminant hepatitis B is transfusion associated?

Tandon: That is very uncommon. In our region, post-transfusion hepatitis occurs at a rate of about $7 \%$. Roughly $70 \%$ of these cases are due to HBV but very few have fulminant disease - perhaps three or four cases out of more than 400 patients.

Kew: Overall, you have reported an extraordinarily high incidence of fulminant acute and 
subacute liver failure. Could this be related to the age at which your population acquires the carrier state? In black Africa, the very high carrier rate is mainly established very early in life at a time when the children are immunotolerant and have asymptomatic disease. If they are infected when they are older, and past the age of immunotolerance, they are more likely to get acute clinical hepatitis but there are far fewer of these cases. Is the hepatitis B carrier state in India a childhood acquired phenomenon or is it acquired later in life?

Tandon: I will present some data on this subject tomorrow. Briefly, the carrier pool is derived from childhood infection $-80 \%$ among the preschool age group. The overall carrier rate in India is $2.5 \%$.

Yao: In China, the incidence of acute fulminant hepatitis has been decreasing in the past decade but cases of cirrhosis of the liver due to chronic hepatitis are increasing. Is this also the case in India?

Tandon: During the past three decades, the incidence of both acute and subacute hepatitis has remained practically the same at my institution. 